\title{
Evidence of early childhood defects due to prenatal over-exposure to vitamin A: a case study
}

\author{
H. Naudé ${ }^{\text {; }}$ J. Marx ${ }^{\text {a; }}$ E. Pretorius ${ }^{\text {a }}$; N. Hislop-Esterhuyzen ${ }^{\text {a }}$ \\ ${ }^{\mathrm{a}}$ University of Pretoria, South Africa
}

\begin{abstract}
One of the important nutrients during pregnancy is vitamin A or related compounds called retinoids. Although it is well-known that vitamin A deficiency may be detrimental to foetal development, overdosage of retinoids might cause developmental defects, particularly affecting the central nervous system development of the foetus, causing hindbrain dysfunction which may be associated with cognitive impairment. Here we discuss a case study based on a 7 years 11 months grade one girl who was prenatally exposed to high dosages of vitamin A. The baby reached her developmental milestones later than expected, she never crawled properly, and she experienced difficulty in maintaining her balance. She suffers from lateral nystagmus and slight strabismus, resulting in diplopia, while tactile defensiveness was also reported. In the current study, the Senior South African Individual Scale - Revised (SSAIS-R) as well as the Quick Neurological Screening Test - Revised Edition (QNST) were performed and this suggested that the hindbrain, the cerebellum and the hippocampus, including related pathways to the parietotemporo-occipital region, were affected. Furthermore, sensory and motor impairment as well as inaccuracy of movements, poor timing and rhythm, compromised spatial perception, and associated somatoperceptual impairment were demonstrated. We conclude that results from the SSAIS-R and the QNST both indicate cognitive impairment that can be linked back to hindbrain impairment and that cognitive impairment due to vitamin A overdose can be assessed using educational testing.
\end{abstract}

\section{Introduction}

Nutrition is extremely important in pregnancy, not only for the well-being of the mother, but also for the optimal development of the foetus. Therefore, the nutritional status of the mother is an important subject discussed in the general literature on pregnancy. However, it is important to note that requirements for many, but not all, micronutrients increase during pregnancy. Deficiencies mainly occur due to malabsorption of the nutrients, or may be due to maternal disease, or even inadequate intakes. In addition, nutrient intake, including dosage and type of nutrient, is extremely important as a lack of knowledge might cause inadequate prenatal nutrition that may be detrimental to the early development of the foetus and ultimately may impact on early childhood development.

One of the important nutrients during pregnancy is vitamin A or related compounds called retinoids. The term retinoids includes both the naturally occurring forms of vitamin A and the many synthetic analogues of retinol, with or without a biological activity (Blomhoff, 1994; Debier \& Larondelle, 2005). Vitamin A is transferred to the foetus from the maternal circulation, and the transfer of retinol, retinaldehyde and retinoic acid has been well documented following the administration of large doses of these compounds to pregnant animals (Clagett-Dame \& DeLuca, 2002). This transplacental transfer is tightly regulated by the homeostasis of the mother. However, blood vitamin A concentrations decline gradually in pregnancy because of haemodilution (an increase in the volume of plasma, resulting in a reduced concentration of red blood cells in blood). Furthermore, research suggests that inadequate dietary vitamin A intake can also lower blood concentrations (Wallingford \& Underwood, 1986). The FAO/WHO suggests that the recommended dietary allowance for vitamin A is $20 \%$ higher for pregnant women than for non-pregnant, non-lactating women. This is particularly because of the need of the foetus, as vitamin A is involved in extensive cell proliferation and development of the foetus (Wallingford \& Underwood, 1986). 
However, although nutrient deficiency is usually the concern during pregnancy, overdosage might have detrimental effects on foetal development. Overdosage of retinoids in particular might cause developmental defects. Areas of foetal development that are dependent on adequate vitamin A are in the central nervous system (Clagett-Dame \& Plum, 1997; Gale et al., 1999; Maden, 1999; Gavalas \& Krumlauf, 2000; Ross et al., 2000; Wendling et al., 2000). However, excess retinoic acid administered during developmental critical periods may result in defects of the central nervous system.

Lammer et al. (1985) gave the first detailed characterization of the teratogenicity of 13-cis RA (Accutane) seen in children of mothers who used the products during pregnancy. Accutane is used as an oral treatment for chronic cystic acne (Peck et al., 1979). When these products emerged on the user scene round about 1982, no negative effects were known at that stage. However, a few years later defects in the early childhood were noted where the product was used during pregnancy. Research revealed that the effects of 13-cis RA on the brain could be divided into two main categories. The first category consists of hindbrain abnormalities sometimes accompanied by hydrocephaly. The abnormalities include major malformations in all hindbrain structures, but most commonly in the cerebellum with agenesis of hypoplasia of the vermis often seen alongside or separate from cranial nerve defects and defects in some of the precerebellar nuclei. The second category consists of forebrain abnormalities, in particular microcephaly or decline in size of specific forebrain regions and occasional cortical heterotopias.

Children with category 1 defects (characterized by hindbrain abnormalities) caused by 13-cis RA embryopathy, generally have marked motor and sensory developmental delays and severe mental retardation (Adams \& Lammer, 1991, 1995; Adams et al., 2001; McCaffery et al., 2003). Of particular interest is the fact that children who were embryonically exposed to 13-cis RA but without major prominent malformations, often exhibit cognitive impairments (Adams \& Lammer, 1991, 1995; Adams \& Holson, 1998; Adams et al., 2001).

The full spectrum of abnormalities associated with human embryonic exposure to 13-cis RA includes a $40 \%$ rate of spontaneous abortion, a $35 \%$ rate of malformation among live-born infants, and a $47 \%$ occurrence of reduced mental ability (Lammer et al., 1987; Adams et al., 2001). Also, neural tube defects (due to high levels of retinoids) were noted (Tibbles \& Wiley, 1988; Griffith \& Wiley, 1991; Griffith \& Zile, 2000). Morphologically cleft palate in retinoic acid treatment results in the foetus presenting with either extreme hypoplasia (underdevelopment) or agenesis (imperfect development) of the palatal shelves and associated with astomia (absence of a mouth), microstomia (unusually small mouth), aglossia (absence of the tongue), microglossia (unusually small tongue) and micrognathia (unnaturally small jaw) with fusion of mandible, maxilla, and zygoma (Padmanabhan \& Ahmed, 1997).

Animal studies (particularly embryonic rodent exposure to retinoids at subteratogenic doses) indicated learning as well as behavioural abnormalities (Adams, 1993; Adams \& Holson, 1998; McCaffery et al., 2003). In rodents, excess administration of vitamin A during the pre-implantation period, as well as during pregnancy, caused eye anomalies that included open eyelids, exophthalmia (protrusion of the eyeballs), cataractous lens, microphthalmia (unnatural smallness of the eyes) and anophthalmia (congenital absence of all eye tissues) (Padmanabhan et al., 1981; Pillans et al., 1988; Emmanouil-Nikoloussi et al., 2000).

As it is known from the literature that over-exposure of vitamin A may cause hindbrain dysfunction associated with cognitive impairment, the current research investigated the cognitive functioning of a subject aged 7 years 11 months who was prenatally exposed to high doses of vitamin A. Here we investigate whether the subjects' cognitive impairment as measured with the Senior South African Individual Scale - Revised (SSAIS-R), as well as dysfunctions noted with the Quick Neurological Screening Test - Revised Edition, can be traced back to hindbrain impairment. 


\section{Case study}

\section{Clinical history}

The subject is an English-speaking girl, aged 7 years 11 months, and in grade one. The girl seems to be somewhat obese with a body weight of $34 \mathrm{~kg}$. She is the only child from an affluent family background, attending a prestigious mainstream primary school(Waterkloof Primary School, Pretoria, South Africa). At the time of her birth, the mother was 43 years of age. During the pregnancy the mother suffered from hypertension, and she followed a diet that consisted mainly of carrots, which she supplemented with high doses of multivitamins. Heavy discolouration (staining) occurred during the last trimester of pregnancy due to vitamin A overload, yet the mother did not adjust her self-imposed diet. During the pregnancy the mother had lost $10 \mathrm{~kg}$ in body weight. The baby was born during the 30th week of gestation, and her birth weight was $2.8 \mathrm{~kg}$. The baby reached her developmental milestones later than expected, she never crawled properly, and she experienced difficulty to maintain her balance, resulting in a fracture of the forearm at the age of one year. She suffers from lateral nystagmus and slight strabismus, resulting in diplopia. Tactile defensiveness was reported. The following facial features are prominent: facial asymmetry, a small jaw, prominently oversized teeth, and unusually small eyes. She attended kindergarten since age three, but did not benefit optimally from this early learning environment, resulting in her having to remain in grade 0 for three years before she had reached reasonable school maturity. On entering grade one, she experienced severe scholastic difficulties of various natures. An EEG revealed abnormal wave activity, but epilepsy was never diagnosed.

\section{Materials and methods}

\section{Materials}

During 2004 the SSAIS-R (Van Eeden, 1992) was administered to determine whether the subject revealed any neuropsychological impairment, and to determine how such impairment might impact on her learning. The SSAIS-R is standardized for South African children between the ages of 7 years 0 months and 16 years 11 months with Afrikaans or English as mother tongue. The SSAIS-R is a point scale (deviation IQ scale) and is based on research data derived from the Wechsler Intelligence Scale for Children - Revised (Wechsler, 1974) and various other authors' descriptions (Kaufman \& Kaufman, 1977; Sattler, 1982; Groth-Marnat, 1984; Van Eeden, 1988; Claassen, 1990). The SSAIS-R is used to obtain a differential image of certain cognitive abilities. In addition, the SSAIS-R renders an individualized profile of relative strengths and weaknesses. Firstly the level of general intelligence is determined, and secondly relative strengths and weaknesses in certain important facets of intelligence are evaluated to obtain diagnostic and prognostic information. The two primary mental abilities measured by the SSAIS-R are a verbal and a non-verbal factor in terms of Thurstone's model. These factors are related to different mental processes and different test contents (Wechsler, 1974). The total score for the subtests of the intelligence scale (the Full Scale or Composite Scale) represents the broader, underlying factor of general intelligence (g). The battery, consisting of a number of relatively independent subtests, makes calculating a general intelligence score possible, as well as an analysis of the performance on the different subtests. The subtests can be divided into two categories on the basis of the item content. The verbal subtests are Vocabulary, Comprehension, Similarities, Number Problems, Story Memory, and Memory for Digits (the latter being optional). The non-verbal subtests are: Pattern Completion, Block Designs, Missing Parts, Form Board, and Coding (the latter being optional).

In addition to the SSAIS-R the Quick Neurological Screening Test - Revised Edition (QNST) (Mutti et al., 1978) was administered to assess neurological integration as it relates to the learning of this subject. The QNST consists of a series of 15 observed tasks that help identify children from age five years up to adulthood, who have learning disabilities. The tasks have been adapted from neurological paediatric examinations and from neuropsychological and developmental scales. During standardization the results of the QNST have also been compared with other instruments, such as the Bender Visual-Motor Gestalt 
Test for Children, the Gesell Developmental Diagnosis, the Denver Developmental Screening Test, and the Meeting Street School Screening Test (Mutti et al., 1978).

The following subtests are included in the QNST (Mutti et al., 1978):

- In the item Hand Skill the subject has to write his or her name at the top of the last page of the recording form, followed by an age-appropriate six-word to eight-word simple sentence.

- In the item Figure Recognition and Production the subject is asked to name each one of a series of five geometric figures, and then draw them. The figures are a circle, a square, a diamond, a triangle, and a rectangle.

- The item Palm Form Recognition consists of asking the subject to identify, solely by touch, numerals drawn on the palm of his or her hands.

- The item Eye Tracking aims at determining whether the subject is able to track a moving object with appropriate eye activity.

- In the item Sound Patterns the subject is asked to reproduce sound patterns after the test administrator demonstrates them.

- In the item Finger to Nose, the test administrator observes motor planning, directionality, and spatial awareness.

- In the item Thumb and Finger Circle fine-motor development is assessed by asking the subject to form successive circles by touching the thumb to each of the fingers (both hands).

- Double Simultaneous Stimulation of Hand and Cheek aims at determining whether the subject is able to feel the gentle touch on the hand at the same time that he or she is touched on the cheek.

- The item Rapidly Reversing Repetitive Hand Movements consists of a series of rapid, repetitive hand movements, in order to observe subtle motor dysfunction.

- In the item Arm and Leg Extension the test administrator assesses muscle tone by checking for random body, hand, or tongue movement, motor tension or impersistence, unusual finger position, tremor or twitching.

- In the item Tandem Walk the subject walks a straight line for at least 10 feet, placing the heel of each shoe directly against the toe of the opposite foot. The subject then walks backward on the 'line', heel-to-toe, and then repeats the tandem walk forward with his eyes closed.

- In the item Stand on One Leg the subject is asked to balance him/herself with eyes open, first on one foot, and then on the other foot, for a count of 10 seconds each.

- In the item Skip the subject is asked to skip across the room, while the test administrator assesses how the subject follows directions and how he/she balances him/herself.

- The item Left-Right Discrimination is scored from parts of three other subtests, namely 'Finger to Nose Location', 'Thumb and Finger Circle' and 'Stand on One Leg'.

- The item Behavioural Irregularities requires general observation of the subject's behaviour during the entire test, such as unusual behaviours, perseveration, excessive talking or withdrawal tendencies, fidgeting, defensiveness, anxiety, excitability, distractibility, and impulsivity, motor planning, and left-right differences.

\section{Data analysis and interpretation}

For analysis and interpretation of the SSAIS-R, the standard deviation method was used to calculate norms for each subtest and for the Verbal, Non-verbal and Full (composite) Scales. Performance is indicated in terms of standard scores or normalized scaled scores.

If a point scale is used, the same intelligence test can be applied throughout to all age groups and the meaning of a particular IQ score remains constant from one age group to the next. An individual's scores on tests or a group of tests, for example the scores obtained on verbal and non-verbal tests, can also be compared with one another. (Van Eeden, 1992, p. 2) 
For analysis and interpretation of the QNST-R, the total score is calculated by tabulating the scores on the 15 subtests. A high score (a total raw score exceeding 50) shows that a child is likely to experience learning difficulties in the regular classroom. A suspicious score (a total raw score exceeding 25, therefore between 26 and 50) usually results from one or more symptoms, which may be developmental or neurological, depending on the age of the child and the severity of the symptom. A normal score (a score of 25 or less) is almost always achieved by individuals who are not likely to have specific learning disabilities (Mutti et al., 1978). Yumahara (1972) undertook a reliability study of the QNST and the results demonstrated statistically high validity. Table 1 presents data showing the significance levels of the $F$ tests in the discriminant analysis for three age groups (Mutti et al., 1978).

Table 1. Distribution of significant $F$ values on subtests of the QNST by age group

$\begin{array}{lc}\text { Group } & \boldsymbol{n} \\ <9 \text { years } & 58 \\ 9-11 \text { years } & 80 \\ \geq 12 \text { years } & 38 \\ \text { Total group } & 176 \\ & \\ \text { ** Correlation significant at } \geq 0.0001 \text { level, } \\ \text { * correlation significant at } \geq 0.05 \text { level. }\end{array}$

$\begin{array}{cl}\text { Mahalanobis } \boldsymbol{D}^{2} & \boldsymbol{F} \\ 9.74 & 7.75^{* *} \\ 6.36 & 7.57^{* *} \\ 7.10 & 3.08^{*} \\ 5.04 & 14.66^{* *}\end{array}$

\section{Results}

\section{IQ test results}

Interpretation of results was done at the 0.01 and 0.05 level of significance (see Table 2). Performance is indicated in terms of standard scores or normalized scaled scores.

Table 2. Reliability coefficients (rtt), specific variances (rtt-h2), error variances (1 - rtt) and standard errors of measurement (SEm) of subtests included in the Verbal, Non-verbal, and Full Scales of the SSAIS-R

$\begin{array}{lcccc}\text { Subtest } & \text { rtt } & \text { rtt-h2 } & \text { 1-rtt } & \text { SEm } \\ \text { Verbal IQ, 86; Non-verbal IQ, 72; Full IQ, 78. } & & & & \\ \text { Vocabulary } & 0.82 & 0.65 & 0.18 & 1.11 \\ \text { Comprehension } & 0.73 & 0.29 & 0.27 & 1.51 \\ \text { Similarities } & 0.78 & 0.40 & 0.22 & 1.60 \\ \text { Number Problems } & 0.79 & 0.27 & 0.21 & 1.34 \\ \text { Story Memory } & 0.85 & 0.39 & 0.15 & 1.33 \\ \text { Pattern Completion } & 0.87 & 0.35 & 0.13 & 1.49 \\ \text { Block Designs } & 0.90 & 0.55 & 0.10 & 0.88 \\ \text { Missing Parts } & 0.67 & 0.45 & 0.33 & 1.74 \\ \text { Form Board } & 0.73 & 0.57 & 0.27 & 1.71\end{array}$

A qualitative interpretation of the results reveals borderline general intellectual functioning on the Full Scale. The subject's verbal capabilities are within the low-average range (Verbal Scale), while the nonverbal capabilities are within the borderline range (Non-verbal Scale). The difference between the verbal and non-verbal scores is statistically significant at the $5 \%$ level of reliability. The scores for the different scales (i.e. Verbal, Non-verbal, and Full Scales) show how the subject performed in comparison with other 
testees in the norm group. However, the evaluation of the subject's relative strengths and weaknesses is not based on any absolute comparison with the norm sample, but with the subject's own level of performance. Therefore an analysis of the subtest scatter was carried out to compile a personal profile of relative strengths and weaknesses in performance. Significant deviations above the average scaled score indicate relative strengths and those significantly below the average, relative weaknesses (Van Eeden, 1992, p. 52).

\section{Analysis of subtest scatter on the Verbal Scale}

An analysis of the subject's performance on different subtests of the Verbal Scale revealed the following strengths and weaknesses (refer to Table 3). The subject revealed significantly higher performance on subtest Vocabulary $(+3.2)$ at both the $5 \%$ and $1 \%$ levels of reliability, indicating a relative strength. Subtest Vocabulary gives a measure of the subject's language development and language usage, in which long-term memory plays a significant role. The subject also scored significantly higher on subtest Comprehension $(+4.2)$ at both the $5 \%$ and $1 \%$ levels of reliability, also indicating a relative strength. Subtest Comprehension gives a measure of the subject's level of social knowledge that is inculcated through everyday experiences and formal training. Long-term memory also plays a significant role in performance on this subtest. The first deduction is that those components of the developing brain that mediate long-term memory might not have been affected by the adverse diet during gestation.

Table 3. Significant deviations of individual scaled scores from the average verbal scaled score: Verbal Scale (scaled score continuum 1-20)

\begin{tabular}{|c|c|c|c|c|}
\hline & \multirow[b]{2}{*}{ Scaled score } & \multirow[b]{2}{*}{ Deviation } & \multicolumn{2}{|c|}{ Signimicant deviauon } \\
\hline & & & $5 \%$ level & $1 \%$ level \\
\hline Vocabulary & 11 & +3.2 & $2.08^{*}$ & $2.74^{* *}$ \\
\hline Comprehension & 12 & +4.2 & $2.06 *$ & $3.42 * *$ \\
\hline Similarities & 10 & +2.2 & 2.72 & 3.58 \\
\hline Number Problems & 4 & -3.8 & $2.37 *$ & $3.12 * *$ \\
\hline Story Memory & 2 & -5.8 & $2.36^{*}$ & $3.11 * *$ \\
\hline Total scaled score & 39 & & & \\
\hline Average scaled score & 7.8 & & & \\
\hline
\end{tabular}

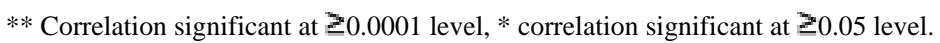

The subject scored significantly lower on subtest Number Problems (-3.8) at both the $5 \%$ and $1 \%$ levels of reliability, indicating a relative weakness. Subtest Number Problems gives a measure of the subject's attained level of spatial orientation (concrete items), logical reasoning, abstract thought, short-term memory and mental alertness. The subject's scaled score on subtest Story Memory was only 2 (scaled score continuum 1-20), which represents a significantly lowered performance at both the $5 \%$ and $1 \%$ level of reliability (-4.8), indicating a relative weakness. These results suggest marked impairment of the shortterm memory. Subtest Story Memory measures short-term auditory memory, as well as sustained attention to auditory stimuli. Lesions to the hippocampus, with its connections to the limbic system might affect short-term memory and memory consolidation (process where declarative memories are gradually encoded into the neocortex) and the overall emotional well being of a person (Robbins et al., 1999; Boylan, 2000; Anderson, 2001; Victor \& Ropper, 2001). The second deduction is that those components of the developing brain that mediate short-term memory might have been affected by the adverse diet during gestation, namely the hippocampus and its neural pathways.

\section{Analyses of subtest scatter on the Non-verbal Scale}

An analysis of the subject's performance on the Non-Verbal Scale revealed statistically significant deviations (refer to Table 4). The subject revealed significantly higher performance on subtest Missing Parts (+3.0) at the 5\% level of reliability, indicating a relative strength. However, this relative strength seems to be a pseudo-strength due to the subject's overall low performance on the Non-verbal Scale, which 
is still below the mean of the average population (i.e. 10.6) (Van Eeden, 1992, p. 24). This subtest measures the ability to distinguish between essential and non-essential visual information and the ability to see the whole in relation to its parts. It also measures flexible gestalt formation and the ability to visually scan the visual field for relevant information by organizing and categorizing visual information. Visual memory might also play a significant role in performance. Flexible gestalt formation, as well as the ability to organize and categorize visual information, also forms an important facet of performance on subtest Block Designs. The subject scored significantly lower on subtest Block Designs (-2.0) at the 5\% level of reliability, indicating a relative weakness. It might thus be interpreted that the subject's visual memory and visual scanning abilities are less adversely affected, although she experiences significant gestalt formation and spatial difficulties, as is evident from her low performance on subtests Number Problems, Pattern Completion, Block Designs, and Form Board. Lesions to the right temporal lobe lead to spatial disorientation problems and difficulties in recognizing complex fragmented, or incomplete, visual stimuli. Loss of the left hippocampus impairs verbal memory in all its modalities, while loss of the right hippocampus results in defective recognition and recall of complex, visual, and auditory patterns, such as are involved in subtests Number Problems, Story Memory, Pattern Completion, Block Designs, and Form Board (Obrzut, 1981; Robbins et al., 1999; Boylan, 2000; Anderson, 2001; Victor \& Ropper, 2001). In addition, the Non-verbal Scale has a heavy motor and spatial input, which suggests involvement of the complex feedback system of pathways with the reticular formation, the basal ganglia, the motor cortex, and the hindbrain, specifically the cerebellum. The cerebellum is involved in motor learning and is able to control well-ingrained motor acts and skills, and integrate their execution so that they are co-coordinated with the entire body (Levinthal, 1983). Damage to the cerebellum is thus associated with poor cerebellumcortex integration. Damage to the basal ganglia may result in poor body posture, uncoordinated hand-eye movements, low muscle tone and slow and inaccurate execution of motor tasks. The third deduction is that those components of the developing brain that mediate well-ingrained motor acts and skills, body posture, coordinated hand-eye movements, muscle tone and execution of motor tasks might have been affected by the adverse diet during gestation, namely the hindbrain, cerebellum and pathways with the reticular formation.

Table 4. Significant deviations of individual scaled scores from the average non-verbal scaled score: Non-verbal Scale (scaled score continuum 1-20)

\section{Scaled score Deviation}

Pattern Completion

Block Designs

Missing Parts

Form Board

Total scaled score

Average scaled score

$\begin{array}{cccc}6 & - & 2.60 & 3.42 \\ 4 & -2.0 & 1.99 * & 2.63 \\ 9 & +3.0 & 2.88^{*} & 3.79 \\ 5 & +1.0 & 2.85 & 3.75 \\ 24 & & & \\ 6.0 & & & \end{array}$

\section{Significant deviation

$5 \%$ level $\quad 1 \%$ level

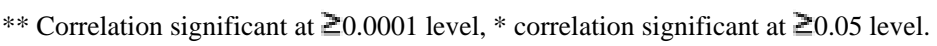

\section{Analysis of subtest scatter on the Full Scale}

Analysis of the Full Scale subtest scatter supports the previous deductions based on the analyses of the Verbal and Non-verbal Scales respectively (refer to Table 5). Any further discussion of the scatter found on the Full Scale is consequently regarded unnecessary. 
Table 5. Significant deviations of individual scaled scores from the average full scaled score: Full Scale (scaled score continuum 1-20)

\begin{tabular}{|c|c|c|c|c|}
\hline & & & $\underline{\text { Signifi }}$ & viation \\
\hline & Scaled score & Deviation & $5 \%$ level & $1 \%$ level \\
\hline Vocabulary & 11 & +4.0 & $2.16^{*}$ & $2.84 * *$ \\
\hline Comprehension & 12 & +5.0 & $2.79 *$ & $3.68 * *$ \\
\hline Similarities & 10 & +3.0 & $2.94^{*}$ & 3.87 \\
\hline Number Problems & 4 & -3.0 & $2.52 *$ & 3.32 \\
\hline Story Memory & 2 & -5.0 & $2.50 *$ & $3.30 * *$ \\
\hline Pattern Completion & 6 & -1.0 & 2.76 & 3.63 \\
\hline Block Designs & 4 & -3.0 & $1.82 *$ & $2.39 * *$ \\
\hline Missing Parts & 9 & +2.0 & 3.17 & 4.17 \\
\hline Form Board & 5 & -2.0 & 3.12 & 4.10 \\
\hline Total scaled score & 63 & & & \\
\hline Average scaled score & 7.0 & & & \\
\hline
\end{tabular}

** Correlation significant at $\geq 0.0001$ level, * correlation significant at $\geq 0.05$ level.

\section{Results of the Quick Neurological Screening Test - Revised Edition}

\section{Hand Skill}

The subject kept her eyes close to the paper. Although she held the pencil clumsily she did not reveal suspicious levels of incompetence on this subtest, mainly because printing is not scored if younger than age eight, and because observable tremor was not exhibited.

\section{Figure Recognition and Production (similar to subtest Block Design of SSAIS-R)}

The subject revealed high levels of inadequacy, as she experienced difficulties with figure recognition and production, especially slow motor tempo, irregular reproduction of figures, poor closure, and poor angle execution. Spatial Orientation also seems to be compromised (i.e. reversal of letters and numbers occurred). She directed herself by means of subvocalization. Poor muscle tone might be associated with lesions of the basal nuclei. The basal nuclei modulate the activation of upper motor neurons that are required for normal initiation of voluntary movements, either during the anticipation of a movement or during the movement itself. Basal nuclei dysfunction results in the loss of a person's ability to switch smoothly between cerebral commands that initiate a movement and those that terminate a movement (Kolb \& Wishaw, 2003, p.70). Most often the cerebral lesion disturbs several systems involved in figure recognition and reproduction.

\section{Palm Form Recognition}

The subject revealed high levels of incompetence, suggesting seriously impaired tactile perception. Damage to the postcentral gyrus is typically associated with marked changes in somatosensory thresholds; that is, impaired position sense and deficits in stereognosis (tactile perception) (Kolb \& Wishaw, 2003, p. 354). The subject performed poorly at detecting touch to the skin (pressure sensitivity). 


\section{Eye Tracking}

The subject revealed high levels of incompetence. She exhibited horizontal and vertical jerkiness and incoordination of eye movements, suggesting posterior parietal impairment in addition to cerebellum impairment. The posterior parietal neurons are responsive to movements of the eyes and to the location of the eye in its socket, regulating the size of the eye movement (saccade) necessary to move the visual target to the fovea of the retina (Kolb \& Wishaw, 2003, p. 350).

\section{Sound Patterns}

The subject revealed suspicious levels of incompetence. She missed sound sequences, and experienced difficulty with simultaneousness and rhythm; she consistently displayed perseveration, and missed motor reproduction of sound patterns. The cerebellum has a role in the timing of movements and in the maintenance of movement accuracy (Keele \& Ivry, 1991; Thatch et al., 1992).

\section{Finger to Nose}

The subject revealed a serious level of incompetence with regards to spatial orientation, pointing towards disturbed orientation of concrete space, associated with cerebellum and parietal lobe functioning. Results derived from this item suggest poor direction within personal space (i.e. to discriminate between left and right, in front and behind, above and beneath). Visual processing in humans does not culminate in secondary visual areas, but continues within multiple visual regions in the parietal, temporal and frontal lobes. It is suggested that this subtest measures visual space and movement accuracy within space; that is, egocentric and allocentric space involved in motor planning, directionality, and spatial awareness. The subject's sense of egocentric and allocentric space is severely compromised, suggesting involvement of multiple neural pathways.

\section{Thumb and Finger Circle}

The subject revealed high levels of inadequacy. She demonstrated overflow of movement in fingers of the opposite hand, indicated flat, constricted or incomplete circles, and manifested confusion regarding the sequence of finger movements, and she skipped fingers. Tonguing (pushing of tongue out of the mouth, usually at the corner of the mouth) also occurred while performing the task. Once again cerebellum involvement is suggested by the subject's inability to maintain movement accuracy, sequence and timing (Keele \& Ivry, 1991; Thatch et al., 1992.

\section{Double Simultaneous Stimulation of Hand and Cheek}

The subject revealed high levels of inadequacy, and she constantly did not feel hand stimulation on one or both sides. This somatoperceptual disorder is referred to as simultaneous extinction, suggesting parietal involvement. Two tactile stimuli were presented simultaneously to different body parts, yet she could only identify one stimulus. A failure to report one stimulus is usually called extinction and is most commonly associated with damage to the somatic secondary cortex, especially in the right parietal lobe (Kolb \& Wishaw, 2003, p. 355).

\section{Rapidly Reversing Repetitive Hand Movements}

The subject revealed high levels of inadequacy, and asymmetry also manifested. She experienced serious difficulty with regards to timing and tempo of movements, as well as muscle tone, suggesting cerebellum involvement. 


\section{Arm and Leg Extension}

The subject revealed high levels of inadequacy. Hypotonic tendencies were observed, as well as an inability to hold position of extremities, pointing towards inadequate muscle tone development associated with compromised cerebellum functioning.

\section{Tandem Walk}

The subject revealed high levels of inadequacy. She could not execute the task backwardly, she stepped onto her own toes, she demonstrated poor balance and difficulty maintaining an upright stance (arm waving), and she revealed involuntary motion not related to balance maintenance. She could not execute the task with eyes closed, suggesting that in addition to poor balance maintenance, she also experiences difficulty associated with spatial orientation. Various neural systems and pathways are involved in this task, as it relates to movement accuracy, maintenance of balance, as well as egocentric and allocentric space awareness.

\section{Stand on one leg}

The subject revealed suspicious levels of incompetence, associated with poor balance and impaired spatial orientation. Once again various neural systems and pathways are involved in this task, as it relates to maintenance of balance in combination with egocentric and allocentric space awareness.

\section{Skip}

The subject could not perform at all, which represents a serious level of incompetence, associated with poor balance and clumsiness. Inability to perform is significant after age six with girls, suggesting cerebellum involvement in the timing of movements and in the maintenance of movement accuracy (Keele \& Ivry, 1991; Thatch et al., 1992).

\section{Left-Right Discrimination}

The subject revealed high levels of inadequacy, as this subtest is scored from parts of three other subtests, namely 'Finger to Nose Location', 'Thumb and Finger Circle' and 'Stand on One Leg', all of these pointing to compromised left-right discrimination.

\section{Behavioural Irregularities}

The subject displayed withdrawal symptoms, fidgeted excessively, and she displayed distractibility, which behavioural irregularities suggest a high level of neural impairment.

The preceding difficulties can also be noted from her drawings, as depicted in Figures 1-5. Although drawing deficits can arise subsequent to lesions in either hemisphere, the deficits in drawing are generally believed to be greater after damage to the right hemisphere, as it is believed to have the greatest influence on drawing ability (Kolb \& Wishaw, 2003, p. 361). Compromised right parietal lobe functioning was also suggested by the presence of simultaneous extinction (refer to Double Simultaneous Stimulation of Hand and Cheek). 


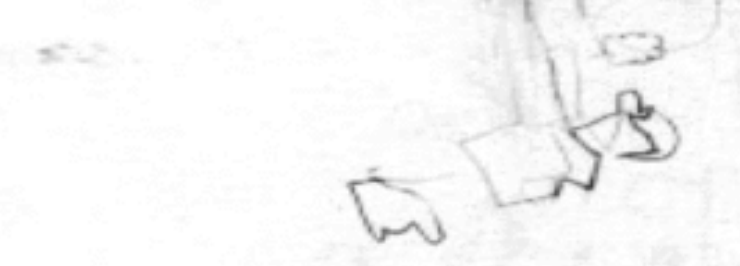

Figure 1. Draw a person (male)

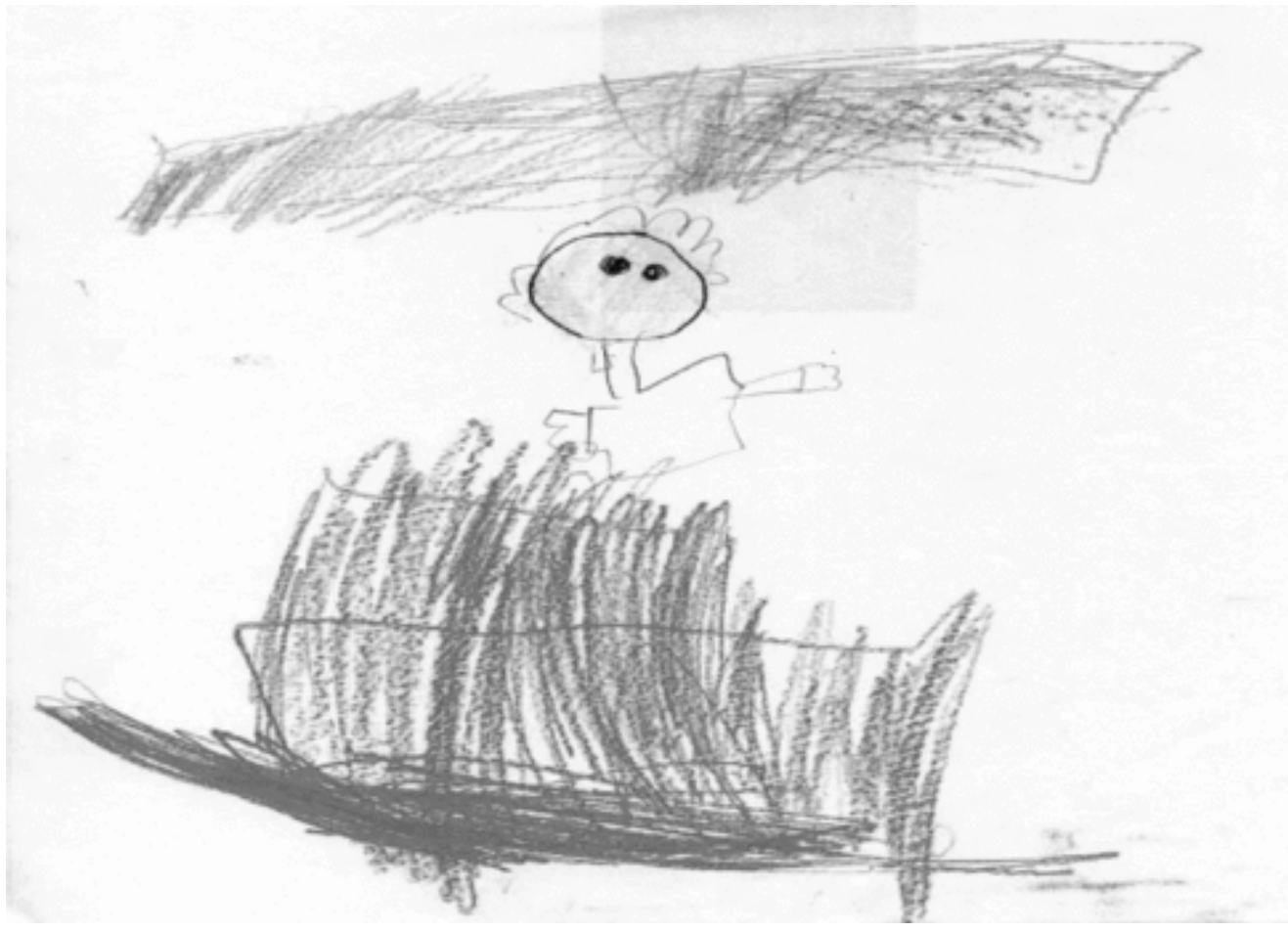

Figure 2. Draw a person (female) 


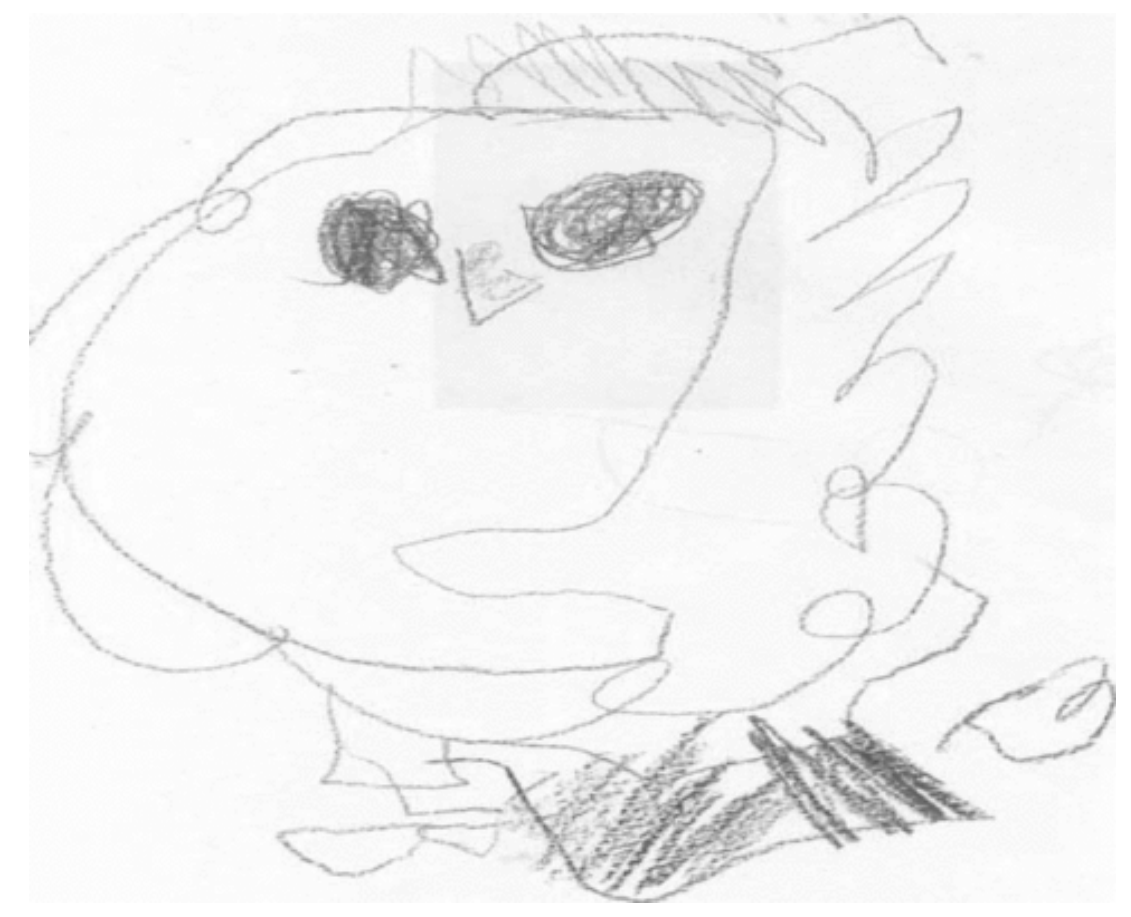

Figure 3. Self-portrait

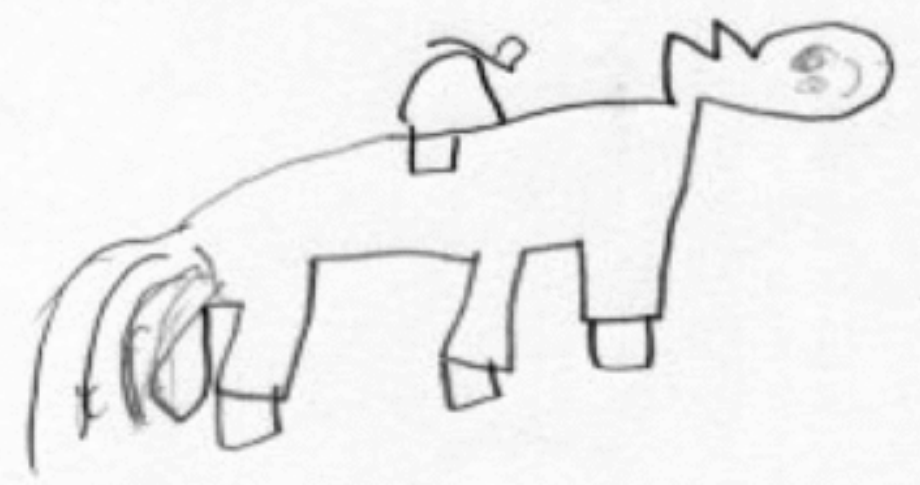

Figure 4. My pet (a horse) 


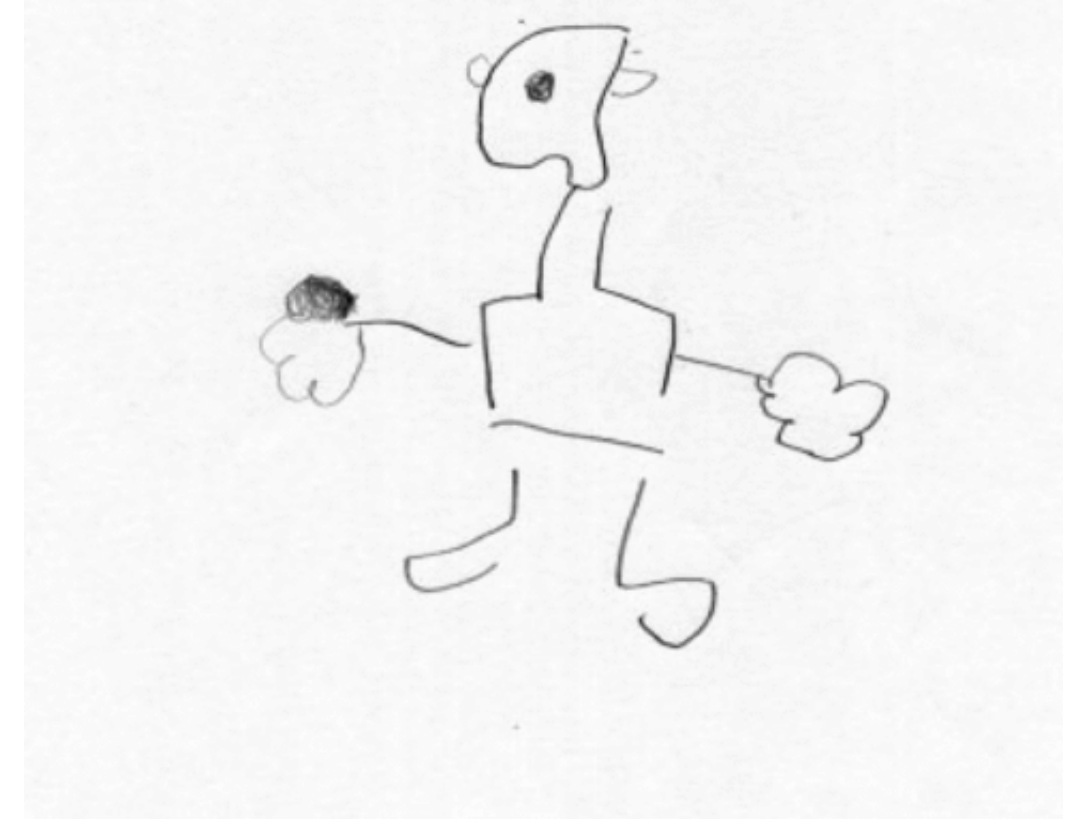

Figure 5. My teacher

\section{Discussion}

The post-facto nature of this case study can be viewed as a methodological limitation. Unfortunately, associated problems due to excess vitamin A intake during gestation can only be detected during postnatal investigations. If the side effects of high vitamin A intake were not reported by the mother and then intentionally investigated, a differential diagnosis might have suggested some other primary diagnosis. Notwithstanding this limitation, the preceding results suggest that the hindbrain, the cerebellum and the hippocampus, including related pathways to the parieto-temporo-occipital region, were likely to be a lesion during gestation. The preceding results suggest sensory and motor impairment. Sensory nuclei of the vestibular system, the sensory system that governs balance and orientation, lie above the fourth ventricle, while more motor nuclei of the cranial nerves lie beneath the fourth ventricle (Kolb \& Wishaw, 2003, p. 60). Involvement of the hindbrain in postural maintenance, as well as in sensory and motor functioning, suggest that excess intake of vitamin A might hamper hindbrain differentiation during gestation. The cerebellum is viewed as part of the motor system that participates in acquiring and maintaining motor skills of diverse nature (Kolb \& Wishaw, 2003, p. 216). The cerebellum can be divided into different regions, each specializing in a different aspect of motor control. The flocculus takes part in the control of balance and eye movements, and impairment reflected in the subject's poor eye tracking, as well as horizontal and vertical jerkiness and incoordination. The most medial parts of the cerebellum control the face and the midline of the body. The more lateral parts are connected to areas of the motor cortex and are associated with movements of the limbs, hands and feet (Kolb \& Wishaw, 2003, p. 217). Furthermore, the cerebellum has a role in the timing of movements and assists to maintain movement accuracy (Keele \& Ivry, 1991). Based upon the results of the QNST-R, difficulty related to poor timing and rhythmic tapping might be ascribed to cerebellum functioning as it relates to loss of timing, both in movement and in perception. According to Thatch et al. (1992) the cerebellum is also associated with keeping movements accurate. According to Thompson (1986, p. 941) the cerebellum is also involved in motor memory as the motor regions of the cortex also receive projections through the thalamus from the cerebellum (Kolb \& Wishaw, 2003, p. 457). Inaccuracy of movements, poor timing and rhythm, compromised spatial perception, and associated somatoperceptual impairment are eloquently demonstrated by the subject's drawings (see Figures 1-5). 
Previous research indicated that an overdose of vitamin A during pregnancy might cause hindbrain defects associated with marked motor and sensory developmental delays. Results from the SSAIS-R and the QNST both indicate cognitive impairment that can be linked back to hindbrain impairment. We therefore conclude by suggesting that cognitive impairment due to vitamin A overdose can be assessed using educational testing. Furthermore, when taking down a subject's case history, overdosage or under-dosage of certain nutrients must also be investigated.

\section{References}

1. Adams, J. (1993) Structure-activity and dose-response relationships in the neural and behavioural teratogenesis of retinoids. Neurotoxicology and Teratology 15 , pp. 193-202.

2. Adams, J., Baer, S., Gavin, J. A. L., Janulewicz, P. A., Meyer, E. and Lammer, E. J. (2001)

Neuropsychological characteristics of children in embryonically exposed to isotretinoin (Accutane): outcome at age 10. Neurotoxicology and Teratology 23 , p. 296.

3. Adams, J. and Holson, R. R. (Slikker, W. S. and Chang, L. W. eds.) (1998) The neurobehavioral teratology of Vitamin A analogs. Handbook of developmental neurotoxicology pp. 631-642. Academic Press, San Diego, CA

4. Adams, J. and Lammer, E. J. (Fujii, T. and Boer, G. J. eds.) (1991) Relationship between dysmorphology and neuro-psychological function in children exposed to isotretinoin 'in utero'. Functional neuroteratology of short term exposure to drugs pp. 159-170. Tokyo University Press , Tokyo

5. Adams, J. and Lammer, E. J. (1995) Human isotretinoin exposure: the teratogenesis of syndrome of cognitive defects. Neurotoxicology and Teratology 17 , p. 386.

6. Anderson, J. R. (2001) Herpes simplex encephalitis. Current Topics in Microbiology and Immunology 253 , pp. 277-282.

7. Blomhoff, R. (Blomhoff, R. ed.) (1994) Overview of vitamin A metabolism and function. Vitamin A in health and disease pp. 1-35. Marcel Dekker, New York

8. Boylan, L. S. (2000) Limbic encephalitis and late-onset psychosis. The American Journal of Psychology 157:(8) , pp. 1343-1344.

9. Claassen, S. P. (1990) Die Wechslerintelligensieskale vir volwassenes: 'n Literatuurstudie (Kantoorverslag 1990/2) Raad vir Geesteswetenskaplike Navorsing , Pretoria

10. Clagett-Dame, M. and DeLuca, H. F. (2002) The role of vitamin A in mammalian reproduction and embryonic development. Annual Review of Nutrition 22 , pp. 347-381.

11. Clagett-Dame, M. and Plum, L. A. (1997) Retinoid-regulated gene expression in neural development. Critical Reviews in Eukaryotic Gene Expression 7 , pp. 299-342.

12. Debier, C. and Larondelle, Y. (2005) Vitamins A and E: metabolism, roles and transfer to offspring. British Journal of Nutrition 93 , pp. 153-174.

13. Emmanouil-Nikoloussi, E. N., Goret-Nicaise, M., Foroglou, C. H., Katsarma, E., Dhem, A., Dourov, N., Persaud, T. V. and Thliveris, J. A. (2000) Craniofacial abnormalities induced by retinoic acid: a preliminary histological and scanning electron microscopic (SEM) study. Experimental and Toxicologic Pathology: Official Journal of the Gesellschaft fur Toxikologische Pathologie 52:(5) , pp. 445-453.

14. Gale, E., Zile, M. and Maden, M. (1999) Hindbrain respecification in the retinoid-deficient quail. Mechanisms of Development 89 , pp. 43-54. 
15. Gavalas, A. and Krumlauf, R. (2000) Retinoid signalling and hindbrain patterning. Current Opinion in Genetics \& Development 10 , pp. 380-386.

16. Griffith, C. M. and Wiley, M. J. (1991) Effects of retinoic acid on chick tail bud development. Teratology 43 , pp. 217-224.

17. Griffith, M. and Zile, M. H. (2000) Retinoic acid, midkine, and defects of secondary neurulation. Teratology 62 , pp. 123-133.

18. Groth-Marnat, G. (1984) Handbook of psychological assessment Van Nostrand Reinhold , New York

19. Kaufman, A. S. and Kaufman, N. L. (1977) Clinical evaluation of young children with the McCarthy scales Grune \& Stratton, New York

20. Keele, S. W. and Ivry, R. (Diamond, A. ed.) (1991) Does the cerebellum provide a common computation for diverse tasks? A timing hypothesis. , Annals of the New York Academy of Sciences 608 , pp. 197-211.

21. Kolb, B. and Wishaw, I. Q. (2003) Fundamentals of human neuropsychology (5th edn), Worth Publishers , New York

22. Lammer, E. J., Chen, D. T., Hoar, R. M., Agnish, N. D., Benke, P. J. and Braun, J. T. (1985) Retinoic acid embryopathy. The New England Journal of Medicine 313 , pp. 837-841.

23. Lammer, E. J., Hayes, E. M., Schunior, A. and Holmes, L. B. (1987) Risks for major malformations among human fetuses exposed to isotretinoin (13-cis retinoic acid). Teratology 35 , p. 68A.

24. Levinthal, C. F. (1983) Introduction to physiological psychology (2nd edn), Prentice-Hall , Englewood Cliffs, NJ

25. Maden, M. (Nau, H. and Blaner, W. S. eds.) (1999) Retinoids in neural development. Handbook of experimental pharmacology (Vol.139) Retinoids, the biochemical and molecular basis of vitamin a and retinoid action pp. 399-442. Springer-Verlag , Heidelberg

26. McCaffery, P. J., Adams, J., Maden, M. and Rosa-Molinar, E. (2003) Too much of a good thing: retinoic acid as an endogenous regulator of neural differentiation and exogenous teratogen. The European Journal of Neuroscience 18:(3) , pp. 457-472.

27. Mutti, M., Sterling, H. M. and Spalding, N. V. (1978) QNST) Quick Neurological Screening Test. Revised edition CA, Academic Therapeutic Publications , Navato

28. Obrzut, J. E. (Hynd, G. W. and Obrzut, J. E. eds.) (1981) Neuropsychological procedures with school-aged children. Neuropsychological assessment and the school-age child: issues and procedures pp. 237-276. Grune \& Stratton, New York

29. Padmanabhan, R. and Ahmed, I. (1997) Retinoic acid-induced asymmetric craniofacial growth and cleft palate in the TO mouse fetus. Reproductive Toxicology 11:(6) , pp. 843-860.

30. Padmanabhan, R., Singh, G. and Singh, S. (1981) Malformations of the eye resulting from maternal hypervitaminosis A during gestation in the rat. Acta Anatomica 110:(4) , pp. 291-298.

31. Peck, G. L., Olsen, T. G., Yoder, F. W., Strauss, J. S., Downing, D. T., Pandya, M., Butkus, D. and Arnaud-Battandier, J. (1979) Prolonged remissions of cystic and conglobate acne with 13-cis-retinoic acid. The New England Journal of Medicine 300 , pp. 329-333.

32. Pillans, P. I., Folb, P. I. and Ponzi, S. F. (1988) The effects of in vivo administration of teratogenic doses of vitamin A during the preimplantation period in the mouse. Teratology 37:(1) , pp. 7-11. 
33. Robbins, S. L., Cotran, R. S., Kumar, V. and Collins, T. (Schoen, F. J. ed.) (1999) Infections of the central nervous system. Pathological basis of disease pp. 1314-1326. (6th edn), Saunders, Philadelphia, PA

34. Ross, S. A., McCaffery, P. J., Drager, U. C. and De Luca, L. M. (2000) Retinoids in embryonal development. Physiological Reviews 80:(3) , pp. 1021-1054.

35. Sattler, J. M. (1982) Assessment of children's intelligence and special abilities (2nd edn), Allyn \& Bacon , Boston, MA

36. Thatch, W. T., Goodkin, H. P. and Keating, J. G. (1992) The cerebellum and the adaptive coordination of movement. Annual Review of Neuroscience 15 , pp. 403-442.

37. Thompson, R. F. (1986) The neurobiology of learning and memory. Science 233 , pp. 941-947.

38. Tibbles, L. and Wiley, M. J. (1988) A comparative study of the effects of retinoic acid given during the critical period of inducing spina bifida in mica and hamsters. Teratology 37 , pp. 113-125.

39. Van Eeden, R. (1988) Die herstandaardisering van die Senior Suid-Afrikaanse Individuele Skaal (SSAIS) vir blanke leerlinge en die standaardisering daarvan vir Kleurling- en Indiërleerlinge: Itemontledingsverslag (Kantoorverslag 1988/21) Raad vir Geesteswetenskaplike Navorsing , Pretoria

40. Van Eeden, R. (1992) Manual for the Senior South African Individual Scale - Revised (SSAIS-R). (Part 1 Background and standardization) Human Science Research Council , Pretoria

41. Victor, M. and Roppper, A. H. (2001) Adams and Victor's principles of neuroanatomy (7th edn), McGrawHill , New York

42. Wallingford, J. C. and Underwood, B. A. (Bauernfeind, J. C. ed.) (1986) Vitamin A deficiency in pregnancy, lactation and the nursing child. Vitamin A deficiency and its control pp. 101-152. Academic Press , New York

43. Wechsler, D. (1974) Manual for the Wechsler Intelligence Scale for Children - Revised (WISC-R) Psychological Corporation, New York

44. Wendling, O., Dennefeld, C., Chambon, P. and Mark, M. (2000) Retinoid signalling is essential for patterning the endoderm of the third and fourth pharyngeal arches. Development 127 , pp. 1553-1562.

45. Yumahara, G. (1972) A reliability study on the Quick Neurological Screening Test San José , Master's thesis, California State University 